of the discovery of polyoma virus in his laboratory and the subsequent work of Stewart and Eddy who, although the first to propagate the virus in cells in tissue culture, most certainly did not discover it, contrary to popular misconception.

This edition has been brought up to date in the sense that more than half a dozen new chapters have been added and many of the old chapters have been revised. But everything has been written in the same spirit as the 1961 edition. Gross's preoccupation is with the history of the discovery of tumour viruses to the exclusion of more recent work. It seems incredible, for example, that in the newly written chapter on SV40 virus both the author and his editors are content to say, "Because virus-containing inclusions in the cytoplasm were found to be Feulgen positive it may be assumed that SV40 is a DNA virus", when one group is already attempting to attach with enzymes $E$. coli genes to SV40 DNA, infect cells with the hybrid molecules and see if the bacterial genes are expressed in a eukaryotic environment.

On the other hand, viewed as a work of history on a grand scale by one of the grand old men of oncogenic virology, Gross's book provides a fascinating historical perspective by drawing attention to the extensive roots of the subject in the late nineteenth and early twentieth century literature. And there are, after all, more than enough publications of one sort or another devoted to the molecular biology of tumour viruses to complement this individual book.

JOHN TOOZE

\section{HELICES OR COILS}

\section{Theory of Helix-Coil Transitions in Biopolymers}

Statistical Mechanical Theory of Order--Disorder Transitions in Biological Macromolecules. By Douglas Poland and Harold Scheraga. (Molecular Biology: an International Series of Monographs and Textbooks.) Pp. xvii + 797. (Academic Press: New York and London, January 1970.) 182s.

THE current spate of monographs on various aspects of molecular biophysics provides a welcome breathing space in the development of the subject encouraging, as it does, an appraisal of some twenty years' frenzied activity in understanding the behaviour of biological macromolecules. Following the proposals that some biopolymers might have regular helical conformations, and encouraged by the relative ease with which one-dimensional systems can be treated in theoretical physics, the problem of helix-coil transitions has attracted considerable interest and some of the consequent literature has becn presented and reviewed in this monograph.

True to its title the book concentrates entirely on the theoretical aspects of helix-coil transitions which resolve, essentially, into the problem of setting up and evaluating the partition functions for a one-dimensional, cooperative system of units which can exist in either of two states ("helix" or "coil"). The text develops these partition functions and their consequences for increasingly complex models in a variety of approximations dealing, first, with the models for polyamino-acids and then, with more difficulty, the nucleic acids. The fundamental interactions which lead to helix stability are not considered and enter the theories only as statistical weighting parameters. Though some attempt has been made to unify the notation, the authors stopped short of complete unification by using two sets of notations (Zirnm-Bragg and Lifson-Roig) in parallel throughout, and the book is made no less uncomfortable to read by tho extensive cross-referencing of equations. By far the best chapter of the book is the penultimate, which gives a general discussion of ensembles and their partition functions together with examples of their use in other one-dimensional topies in physical chemistry. This chapter elarifies much of the previous discussion and it seems a pity that it is not presented earlier in the text. The latter half of the book is given over to roprints of no less than forty-four original papers selected almost entirely from the theoretical litorature except for a few of the classic papers on the $\alpha$-helix and DNA double helix. The inclusion here of some representative papers from the experimental literature on helix-coil transitions in solution might have viven weight to the theories and would, at least, have provided a little light relief.

Ir. a paper published in 1968 (and not reproduced in this monograph), D. S. Olander and A. Holtzer pointed out that "poly-L-glutamic acid forms a very stable $\alpha$-helix, whereas poly-L-aspartic acid forms almost no helix, and no one has the vaguest notion why". No book written at the present time can be faulted for not resolving this problem, but what is disturbing about a book "intended as an introduction, review, and reference for students" is that no hint is given that such fundamental gaps in our understanding of the problem exist at all. A student reading this book could be forgiven for concluding that the problem of helix-coil transitions is merely ono of mathematical expertise rather than basic physical understanding.

Alan COOPER

\section{MEMBRANE PROTEINS}

\section{Membrane Proteins}

Proceedings of a Symposium sponsored by the New York Heart Association. Pp. 360. (Churchill: London, 1969.) $75 s$.

Most biological membranes contain about 50 per cent by weight of protein, and each cell has at least six different types of membranes each of which probably contains a considerable number of different proteins, yet this symposium does not deal with more than about a dozen proteins. Such an observation is not in any way a criticism, for the book's contents illustrate the remarkable progress made in a few cases, and its omissions, if the reader considers them, indicate our almost total ignorance of the functioning of most proteins in most membranes.

Two transport systems are extensively discussed, and these are the two that have been most amenable to analysis, the sodium/potassium pump (Glynn and Lew, Post et al., Hokin, Hoffman), and sugar entry into bacteria (Kennedy, Heppel, Roseman). Both sets of studies show how activity depends on the integrity of a lipoprotein complex anisotropically arrayed in the membrane. Synaptic transmission, also a type of transport process, is considered in some detail by a series of papers on the proteins involved. Acetylcholine esterase has been isolated from several membranes, especially the electroplax organ, and the isolated molecule is available for direct analysis (Nachmansohn). The acetylcholine receptor site, on the other hand, has not been isolated as such and continues to be studied by indirect means as, for example, by the use of inhibitors and analogues (Karlin, Silman, Mautner). Not many years ago the study of sugar transport and sodium/potassium movement was equally limited, and considering the recent progress in these two cases one would expect the isolation of the receptor site to belong to the near future -indeed, Changeux et al. discuss the many similarities between it and tho acetylcholine esterase.

These specific eatalytic proteins account for only a small fraction of the total protein of the membranes to which they belong, the function and organization of the remaining protein being a mystery. (Papers by Wallach on protein conformation and McConnell on spin-labelled membranes consider how the organization may be studied in the intact membrane.) Perhaps the one membrane where the functions of the greater part of the constituent 